\title{
Factors associated with baseline mortality in Norwegian Atlantic salmon farming
}

\author{
Victor H. S. Oliveira ${ }^{1 凶}$, Katharine R. Dean ${ }^{1}$, Lars Qviller ${ }^{1}$, Carsten Kirkeby ${ }^{2}$ \& \\ Britt Bang Jensen ${ }^{1}$
}

In 2019, it was estimated that more than 50 million captive Atlantic salmon in Norway died in the final stage of their production in marine cages. This mortality represents a significant economic loss for producers and a need to improve welfare for farmed salmon. Single adverse events, such as algal blooms or infectious disease outbreaks, can explain mass mortality in salmon cages. However, little is known about the production, health, or environmental factors that contribute to their baseline mortality during the sea phase. Here we conducted a retrospective study including 1627 Atlantic salmon cohorts put to sea in 2014-2019. We found that sea lice treatments were associated with Atlantic salmon mortality. In particular, the trend towards non-medicinal sea lice treatments, including thermal delousing, increases Atlantic salmon mortality in the same month the treatment is applied. There were differences in mortality among production zones. Stocking month and weight were other important factors, with the lowest mortality in smaller salmon stocked in August-October. Sea surface temperature and salinity also influenced Atlantic salmon mortality. Knowledge of what affects baseline mortality in Norwegian aquaculture can be used as part of syndromic surveillance and to inform salmon producers on farming practices that can reduce mortality.

High mortality of farmed salmonids results in annual deaths of tens of millions of fish across the world. Reports from some of the leading salmon producing countries (Norway, Chile, and the UK) show that the total mortality is increasing ${ }^{1-3}$. Norway is the world's largest producer of Atlantic salmon (Salmo salar L.). The annual transfers of Atlantic salmon smolts to Norwegian coastal waters peaked at 304 million in 2018. The transfers have remained relatively stable between 2015 and 2019, with less than $2.5 \%$ variation between years ${ }^{4}$. Over this period, the yearly Atlantic salmon deaths has risen $27.8 \%$, from 41.3 to 52.8 million $^{4}$. Reducing mortality in aquaculture is crucial to ensure sustainable production. High mortality also represents major economic losses and is considered an indicator of poor fish welfare 5 . Furthermore, some of the mortality determinants that cause high mortality in farmed salmon may also threaten wild salmon, as they commonly share marine environments and are affected by the same diseases ${ }^{5}$.

Several studies have described regional mortality patterns in Atlantic salmon farms in Northern Europe and Chile. In Norway, previous research found large variations in mortality patterns between geographically separate areas, between years of sea transfer, and at different time points during the production cycle ${ }^{2}$. During the rearing period at sea, the mean mortality per month of three-quarters of the Atlantic salmon cohorts was rarely above $2 \%$, with large variations between farms and years ${ }^{2}$. A proportion of monthly deaths of less than $1 \%$ in individual Norwegian farms was defined as non-extreme mortality in a study from $2018^{6}$. On Scottish farms, regional variation was also detected, with an average monthly mortality that varied between 0.34 and $2.81 \%$ among regions ${ }^{3}$. Another Scottish study reported weekly mortality below $1 \%$ in most farms (90th percentile) ${ }^{7}$. The average monthly mortality in the main Atlantic salmon producing regions of Chile was between 0.38 and $1.78 \%$ in $2018^{1}$. Building on these studies, which describe the mortality patterns in Atlantic salmon farms, the next step is to understand the main determinants of mortality that could be targeted to mitigate deaths.

Preceding mortality events, important indicators of poor welfare can be observed in fish, including behavioral changes, morphological alterations, emaciation, injuries, and other compromised physical conditions $\mathbf{s}^{8,9}$. Mortality is the endpoint of an adverse health condition in the fish. It is caused by a combination of environmental and host factors, and often, one or more pathogens are involved ${ }^{9}$. However, it is difficult to disentangle the mechanisms that play a role in mortality in general. Major infectious agents and parasites contributing to

${ }^{1}$ Norwegian Veterinary Institute, 1433 Ås, Norway. ${ }^{2}$ Department of Veterinary and Animal Sciences, Faculty of Health and Medical Sciences, University of Copenhagen, 1870 Frederiksberg, Denmark. ${ }^{\varpi}$ email: victor.oliveira@ vetinst.no 


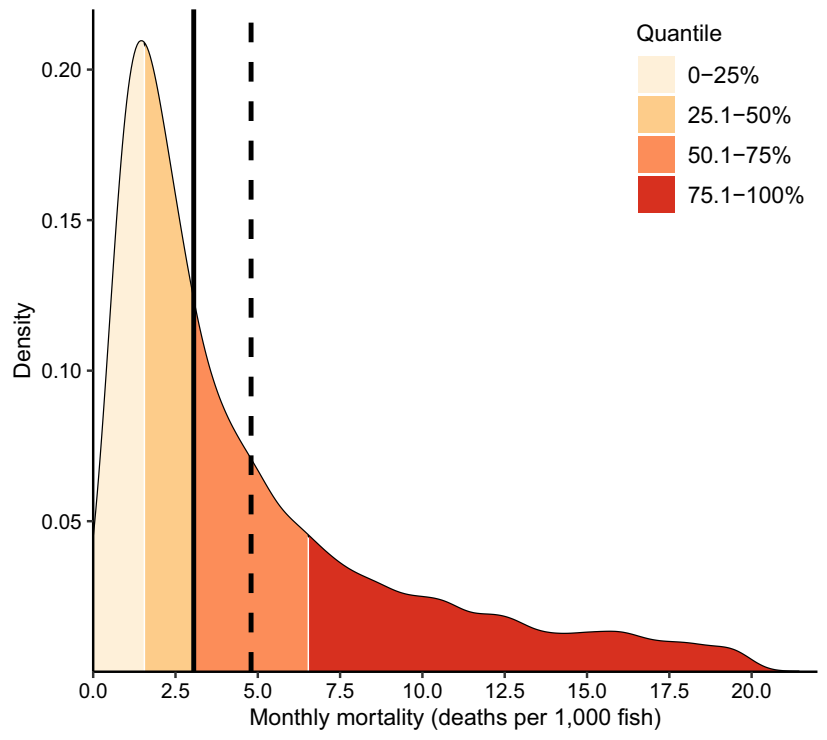

Figure 1. Summaries of monthly mortality distribution between 2014 and 2019 in Norwegian Atlantic salmon farms. The smoothed line is the kernel density estimate, quantiles are represented by colors, the median by the straight line and the mean by the dashed line. This figure was generated using the Tidyverse ${ }^{46}$ package in $\mathrm{R}^{47}$.

mortality in farmed Atlantic salmon include salmonid alphavirus (SAV $)^{10-12}$, infectious salmon anemia virus $(\text { ISAV })^{13,14}$, infectious pancreatic necrosis virus (IPNV $)^{15,16}$, piscine myocarditis virus (PMCV) ${ }^{17,18}$, Moritella viscosa ${ }^{19}$, Renibacterium salmoninarum ${ }^{20}$, sea lice (Lepeophtheirus salmonis and Caligus spp. $)^{21-23}$, and Paramoeba perurans $^{24}$. Coinfections can occur, and those involving viruses (e.g. IPNV and SAV) and sea lice infestations or other infections (e.g. with ISAV and M. viscosa) are associated with higher mortality ${ }^{16,25,26}$.

Environmental factors, including algal blooms and changes in temperature and salinity, are also known for their potential influence on mortality ${ }^{27-30}$. For example, high sea surface temperature and salinity $\left(>12^{\circ} \mathrm{C}\right.$ and $>12 \%$ ) can increase L. salmonis growth and survival rates ${ }^{31,32}$, with effects on Atlantic salmon infestation by the parasite. Similarly, environmental conditions can influence the growth of different species of pathogenic bacteria and toxin-producing algae that are harmful towards Atlantic salmon ${ }^{19,29,30,33}$. In contrast, higher temperatures appear associated with lowered IPNV prevalence within farms ${ }^{16}$.

The susceptibility of the farmed Atlantic salmon to diseases associated with higher mortality may vary throughout the production cycle and according to stocking conditions. Detection of IPNV usually occurs during the first 3 months after the salmon transfer to sea ${ }^{15,16}$, while PMCV affects larger salmon ( $\left.>2 \mathrm{~kg}\right)$, which have spent longer periods at sea ${ }^{17,18}$. Both SAV and $R$. salmoninarum have been detected in salmon across a wide range of ages ${ }^{20,34,35}$. A factor that can also contribute to greater mortality risk is the lack of vaccinations, for example against $\mathrm{SAV}^{36}$ and $M$. viscosa ${ }^{37}$. Management practices adopted by farmers for controlling sea lice in Atlantic salmon constitute another important challenge, particularly in high-density farming areas ${ }^{38}$. Sea lice treatments using hydrogen peroxide $\left(\mathrm{H}_{2} \mathrm{O}_{2}\right)$ baths can be toxic to Atlantic salmon ${ }^{39}$. The development and spread of resistance in sea lice towards medicinal treatments (e.g. emamectin benzoate, organophosphates, and pyrethroids) and $\mathrm{H}_{2} \mathrm{O}_{2}$ bath treatments adds to the burden of the parasite. This has shifted management strategies towards the use of so-called "non-medicinal" treatments, with sea lice removal by warm water, flushing or brushing ${ }^{6,40-42}$. These treatments are considered responsible for inducing trauma and increased mortality in Atlantic salmon ${ }^{41,43-45}$.

To date, most investigations into the mortality determinants in Atlantic salmon farming have focused on specific factors presumed to be associated with extreme mortality, with little research on the factors associated with underlying baseline mortalities during production. Here, the baseline mortality refers to the mortality at a "normal" (or expected) level, not including extraordinary events associated with increased mortality, such as algae blooms or infectious disease outbreaks. The objective of this study was to identify the determinants of the baseline mortality in the Norwegian population of farmed Atlantic salmon and to quantify their effects, using routinely collected environmental, fish health, and production data.

\section{Results}

Description of baseline Atlantic salmon mortality. Our study population consisted of Atlantic salmon put to sea from 1627 cohorts produced on 642 different farms. Among the 14,280 records of the analyzed dataset, the mean number of fish at risk per month was 838,228 (median $=777,328$; interquartile range $[\mathrm{IQR}]=493,233-$ $1,108,106)$. The mean monthly number of dead fish was 4.8 deaths per 1,000 fish (median $=3.05$; IQR $=1.58-$ 6.53) (Fig. 1). We present the descriptive results of salmon mortalities and its putative determinants in plots (Fig. 2) and in data summaries (Table 1).

Model fitting and diagnostics. Models with interactions did not converge and we excluded them from our analysis. The interactions also caused high collinearity problems, confirmed by a variance inflation factor 

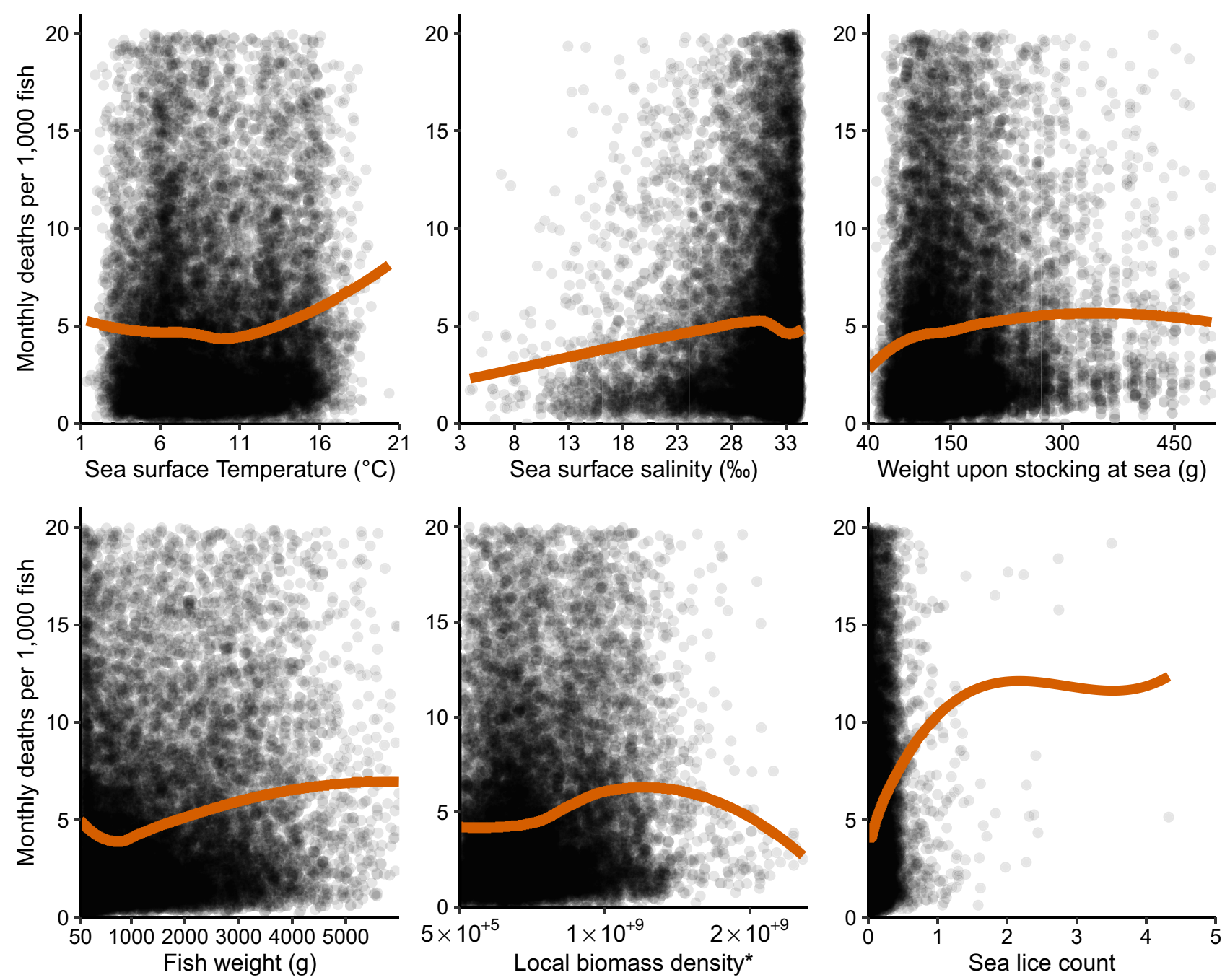

Figure 2. Scatter plots with fitted local polynomial regression (LOESS) curves of mortality versus continuous explanatory variables. *The local biomass density (LBD) of a farm in a certain month is a summarized record of Atlantic salmon biomass (i.e. number of fish multiplied by mean weight) calculated using data from neighboring farms located up to $40 \mathrm{~km}$ seaway distance. For full details on LBD calculations, we refer to Jansen et al. ${ }^{38}$. This figure was generated using the Tidyverse ${ }^{46}$ and gridExtra ${ }^{48}$ packages in $\mathrm{R}^{47}$.

higher than 10. We log-transformed the variable local biomass density for convergence but this variable was later dropped from our model due to lack of significance. We also eliminated the variable for sea lice infestation from models because its inclusion caused a lack of uniformity in the distribution of the standardized residuals. In our final model, the variables sea surface temperature (SST) and fish weight were polynomial terms of the second order. This was due to curvilinear patterns observed in the scatter plots of these variables against the outcome; in addition, we detected considerable improvements of the model fit by including second order polynomial terms. The final multivariable model had eight significant variables $(p<0.05)$ associated with mortality (see Supplementary Table S1 online), which were: SST, sea surface salinity (SSS), production zone, initial weight upon stocking at sea, month of first stocking at sea, fish weight, $\mathrm{H}_{2} \mathrm{O}_{2}$ or medicinal sea lice treatments, and non-medicinal sea lice treatments. There was a borderline difference between this final model, Akaike information criterion $(A I C)=257,353$, and a model without the variable initial weight upon stocking at sea (AIC $=257,355.4)$. The final model intra-class correlation coefficient (ICC) was 0.154 . The variable SSS showed potential confounding effects with the production zone 1 and initial weight upon stocking at sea. We did not detect model fit issues from the residual plots (see Supplementary Fig. S1 online).

Determinants of baseline salmon mortality. Results from the final model of baseline mortality in farmed salmon are presented in a plot with mortality rate ratios (Fig. 3) and plots of predicted mortalities (Figs. 4, 5). For the environmental variables, we predicted higher mortality when the SST was below 5 and above $10{ }^{\circ} \mathrm{C}$ (Fig. 4). Higher SSS had an adverse effect on mortality (Fig. 3); for each additional 5\%o increase in salinity, we estimated that mortality increased by approximately $20 \%$. The production zones with the highest mortality were 2,3 , and 4 (Fig. 3). These zones had approximately 1.5 times higher mortality compared to the production zone 10, which was the least problematic region in terms of mortality. Salmon transferred to sea in July had the 


\begin{tabular}{|c|c|c|c|c|c|}
\hline \multirow[b]{2}{*}{ Variable } & \multirow[b]{2}{*}{ Category } & \multirow[b]{2}{*}{$\mathbf{n}$} & \multicolumn{3}{|c|}{ Monthly deaths per 1000 fish } \\
\hline & & & Mean & Median & $\mathrm{IQR}^{\mathrm{a}}$ \\
\hline \multirow{12}{*}{ Production zone $\mathrm{e}^{\mathrm{b}}$} & 1 & 332 & 4.1 & 2.26 & $1.39-5.69$ \\
\hline & 2 & 939 & 5.36 & 3.76 & $1.79-7.99$ \\
\hline & 3 & 2884 & 5.71 & 4.02 & $1.80-8.44$ \\
\hline & 4 & 2077 & 5.2 & 3.47 & $1.68-7.32$ \\
\hline & 5 & 598 & 4.78 & 3.15 & $1.95-6.02$ \\
\hline & 6 & 1870 & 4.61 & 2.83 & $1.54-6.06$ \\
\hline & 7 & 498 & 3.6 & 2.15 & $1.19-4.39$ \\
\hline & 8 & 1270 & 3.8 & 2.37 & $1.30-4.74$ \\
\hline & 9 & 1136 & 3.66 & 2.29 & $1.20-4.59$ \\
\hline & 10 & 692 & 3.73 & 2.38 & $1.29-4.71$ \\
\hline & 11 & 540 & 5.08 & 3.37 & $1.79-7.10$ \\
\hline & 12 and $13^{c}$ & 1444 & 5.03 & 3.63 & $1.97-6.57$ \\
\hline \multirow{10}{*}{ Month of 1st stocking at sea } & Mar & 1158 & 5.48 & 3.56 & $1.77-8.07$ \\
\hline & Apr & 2561 & 5.29 & 3.60 & $1.80-7.41$ \\
\hline & May & 2173 & 4.7 & 3.07 & $1.63-6.22$ \\
\hline & Jun & 690 & 5.0 & 3.24 & $1.76-7.23$ \\
\hline & Jul & 1046 & 4.88 & 3.37 & $1.78-6.57$ \\
\hline & Aug & 2362 & 4.43 & 2.85 & $1.45-5.97$ \\
\hline & Sep & 2607 & 4.51 & 2.51 & $1.31-6.06$ \\
\hline & Oct & 965 & 4.24 & 2.58 & $1.41-5.47$ \\
\hline & Nov & 298 & 5.18 & 3.79 & $1.49-7.33$ \\
\hline & Dec, Jan and Feb ${ }^{c}$ & 420 & 4.65 & 3.42 & $1.79-6.21$ \\
\hline \multirow{3}{*}{$\mathrm{H}_{2} \mathrm{O}_{2}$ or medicinal treatments ${ }^{\mathrm{d}}$} & Not treated & 11,162 & 4.42 & 2.77 & $1.48-5.84$ \\
\hline & 1 time per month & 2189 & 5.94 & 4.35 & $2.15-8.61$ \\
\hline & $\geq 2$ times per month $^{\mathrm{c}}$ & 929 & 6.63 & 4.97 & $2.21-10.0$ \\
\hline \multirow{3}{*}{ Non-medicinal treatments ${ }^{\mathrm{e}}$} & Not treated & 13,039 & 4.48 & 2.81 & $1.50-5.97$ \\
\hline & 1 time per month & 920 & 7.72 & 6.68 & $3.72-10.8$ \\
\hline & $\geq 2$ times per month $^{c}$ & 321 & 9.2 & 8.66 & $4.58-13.3$ \\
\hline
\end{tabular}

Table 1. Descriptive statistics of categorical explanatory variables versus mortality. ${ }^{\mathrm{a}} I Q R$ interquartile range. ${ }^{b}$ Production zones delimited in Fig. 6. ${ }^{\mathrm{c}}$ Merged category due to few number of observations for one of them. ${ }^{\mathrm{d}}$ Bath treatments using $\mathrm{H}_{2} \mathrm{O}_{2}$ or medicinal compounds, such as azamethiphos and pyrethroids. ${ }^{e}$ Removal of sea lice usually by flushing or brushing, warm water or freshwater baths.

highest mortality compared to salmon transferred to sea in the late summer and fall (Fig. 3). Higher weight at the time of first stocking at sea had a small, negative impact on mortality (Fig. 3). The estimated mortality was high for the smallest fish, but decreased until around $500 \mathrm{~g}$, when the mortality started to increase. We found a pronounced increase in the predicted number of deaths in salmon heavier than $2000 \mathrm{~g}$ (Fig. 5). The most detrimental factor among all the mortality determinants was the use of non-medicinal treatments for sea lice. When salmon were subjected to such treatments, the mortality was almost double than without them. The $\mathrm{H}_{2} \mathrm{O}_{2}$ or medicinal sea lice treatments also influenced the mortality, but to a lesser extent (Fig. 5).

\section{Discussion}

In this study, we identified and quantified important factors that contribute to mortality on Norwegian salmon farms. We explored salmon mortality in a different way compared to previous research, as our focus was on the baseline mortality $(\leq 2 \%)$. This provided a deeper understanding of what determines mortality beyond specific adverse events associated with extreme numbers of deaths. It also supplies the farmers with a way of benchmarking the performance of their farms in relation to national or regional averages. Our study utilized extensive longitudinal data and made use of discrete death counts. The advantage of this approach is that it was possible to adjust mortality predictions to the number of fish at risk of death per month. Furthermore, we relied on data that is routinely collected in Norway, which offers the opportunity to monitor excess deaths on farms by comparing the observed deaths to the expected deaths in a baseline situation.

Previous studies of mortality on salmon farms have used different outcome variables, which can make it difficult to compare results. An earlier study of Norwegian farms modelled the probability of fish deaths ${ }^{2}$. A Scottish study modelled mortality using the proportion of fish biomass lost within a month as the outcome ${ }^{3}$. Using biomass data as the outcome can be a potential source of uncertainty because of variations in the records depending on the stage of the production cycle, as larger fish contribute more to the losses than smaller ones. We calculated mortality based specifically on the counted deaths, and other attributed reasons for fish losses, such as discarded and escaped fish, were excluded. These excluded categories accounted for approximately $10-15 \%$ of the 


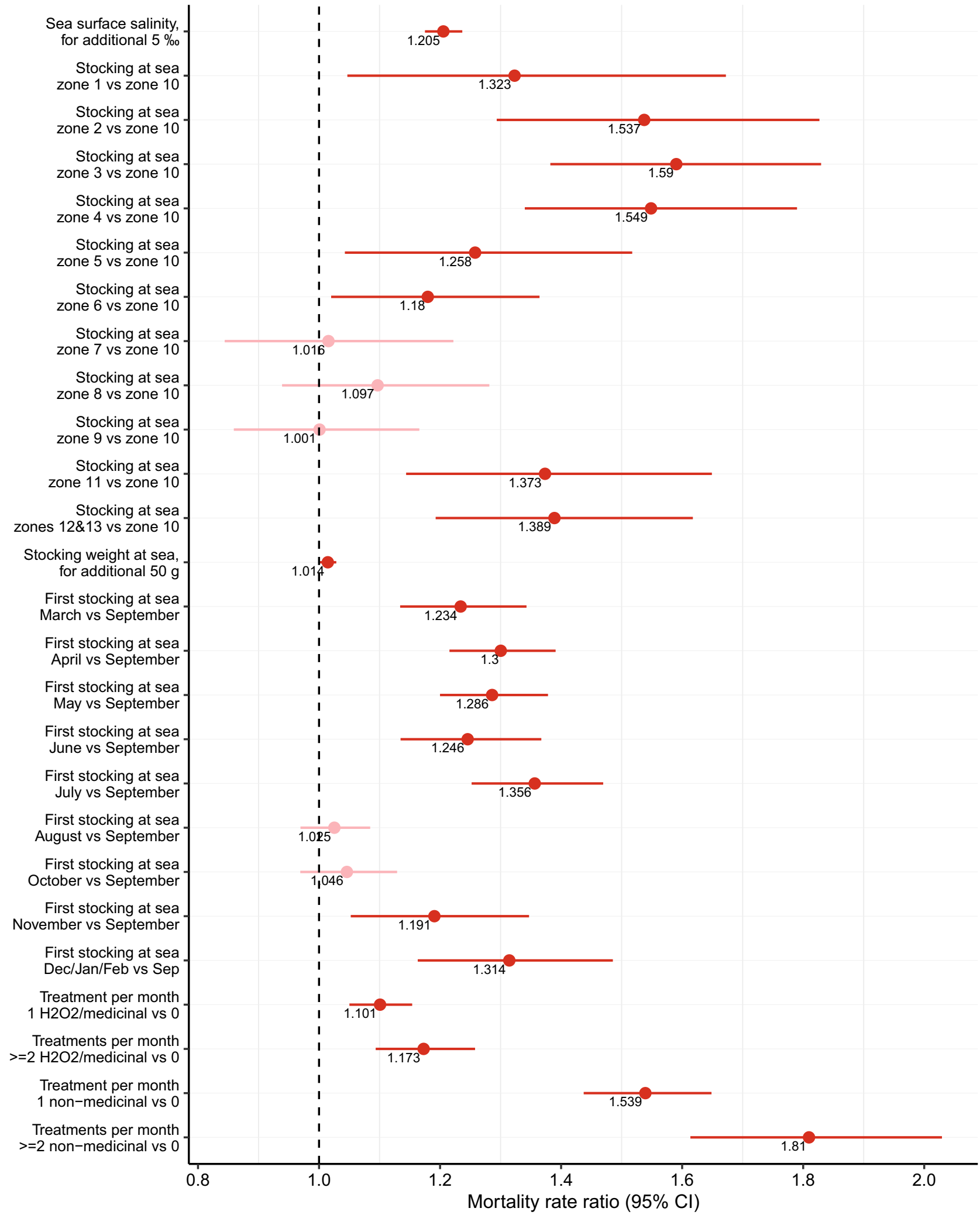

Figure 3. Mortality rate ratio plot with the determinants of baseline mortality in farmed Atlantic salmon. Results of other determinants added as polynomial terms in our mortality model are shown in Figs. 4 and 5. This figure was generated using the Tidyverse ${ }^{46}$ package in $\mathrm{R}^{47}$. 
www.nature.com/scientificreports/

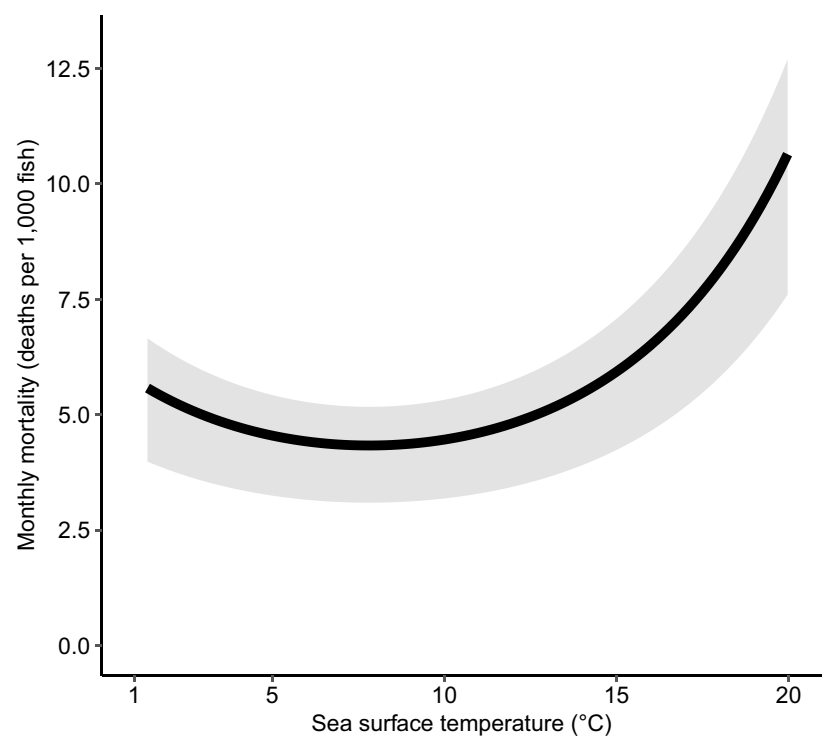

Figure 4. Atlantic salmon mortality predictions from the final model based on sea surface temperature. The lines and shaded areas in the plots show the mean and interquartile range of predicted values, respectively. This figure was generated using the Tidyverse ${ }^{46}$ package in $\mathrm{R}^{47}$.

Number of monthly sea lice treatments

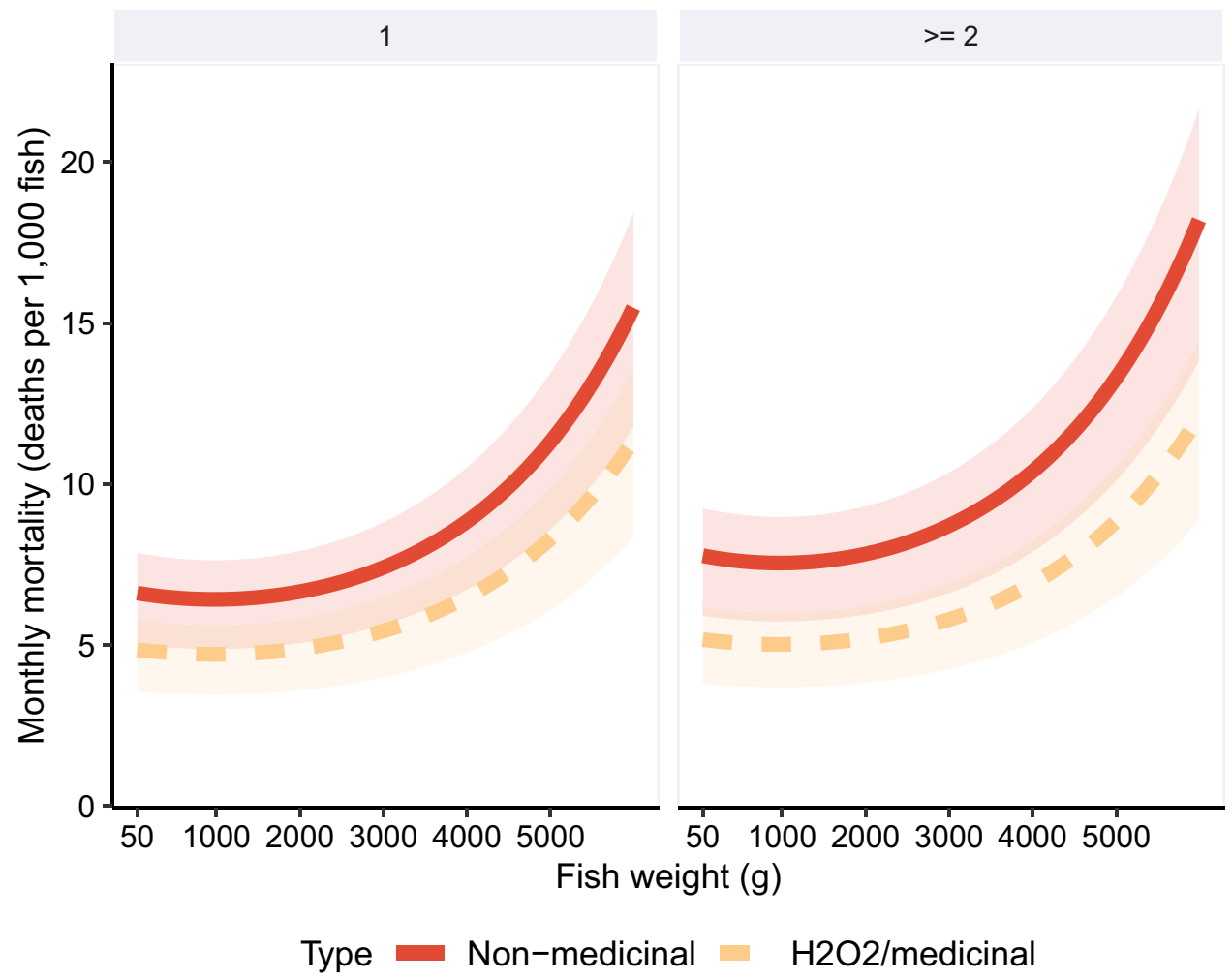

Figure 5. Atlantic salmon mortality predictions from the final model based on fish weight and number of sea lice treatments per month. The lines and shaded areas in the plots show the mean and interquartile range of predicted values, respectively. The different colors represent two types of sea lice treatments for comparisons. One is bath treatments using $\mathrm{H}_{2} \mathrm{O}_{2}$ or medicinal compounds, such as azamethiphos and pyrethroids. The other is non-medicinal treatments with removal of sea lice by flushing or brushing, warm water or freshwater baths. This figure was generated using the Tidyverse ${ }^{46}$ package in $\mathrm{R}^{47}$.

Scientific Reports |

(2021) 11:14702 |

https://doi.org/10.1038/s41598-021-93874-6

nature portfolio

6 
salmon losses between 2015 and 2019 in Norwegian aquaculture ${ }^{4}$. However, using death counts can have some limitations. For example, it was necessary to exclude records from our analyzed dataset due to inconsistencies in the numbers of added and removed fish on some of the farms between consecutive months. These inconsistencies are often related to farm management, such as moving or splitting the fish or having multiple stocking or slaughtering events, which can generate unmatched counts. Access to the detailed production data from the farmers could resolve some of the inconsistencies, as farmers usually keep daily information on movements and data counts. However, such access is often only granted to a subset of the population and, therefore, could introduce biases relating to specific management practices and willingness to provide higher resolution data.

Overall, we found factors related to production, health, and the environment that were determinants of mortality. In terms of production, fish weight can be interpreted as an indicator of the temporal pattern of mortality throughout the production cycle. Hence, our results correspond with others ${ }^{2,49}$, who also found high mortality during the initial 1-3 months at sea (generally when fish grow from 50 to $500 \mathrm{~g}$ ) with a subsequent drop that is followed by a rising trend in mortality until the end of the production. It is reasonable to assume that the higher mortality in older salmon is a consequence of longer periods of fish exposure to mortality determinants. For example, sea lice treatments happens more frequently in the second year in sea. In the initial period at sea, the weekly mortality reached values above $4 \%$. This could be attributed to so-called "failed smolts", when transformation from parr to smolt is not complete ${ }^{7,50}$. In the early stages of salmon adaptation to seawater, hypo-osmoregulatory disturbance, reduced feed intake, and a potential down-regulation of immune responses may increase salmon mortality ${ }^{51,52}$.

Other production related factors that showed effects on mortality were the month and weight at first stocking. Salmon transfers to sea occur throughout the year using smolts from season (or "S1") and off-season (or "S0") production, which are distinct in terms of the transfer age. In general, the S1 smolts are more than 1 year old and transferred during spring, whereas the S0 can be transferred at a younger age during autumn ${ }^{53}$. Our study revealed a lower mortality when the transfers occurred between August (late summer) and October (autumn), which is comparable with previous research that found lower mortality of S0 smolts in the 90 days post-transfer period comparing to $\mathrm{S} 1$ smolts $^{54}$. In addition to the stocking month, the starting weight of fish seemed to have adversely affected mortality the higher it was. This result is in agreement with others ${ }^{55}$, who suggested that potential desmoltification of larger fish could be an issue. The transfer of smolts to sea generally occurs when fish weigh less than $150 \mathrm{~g}^{56}$. By contrast, the transfer of larger smolts to sea can be defended as a way to minimize exposure of the host to sea lice and other infectious agents during their life cycle. There are now protocols for land-based systems to rear larger salmon (up to $450 \mathrm{~g}$ ) prior to the sea transfer ${ }^{28}$. However, we did not detect a protective effect from stocking larger smolt and the observed effect of variations in the initial weight for the transfer were generally small in our study.

Apart from management factors, we found health-related factors that were associated with mortality including production zone and the number of sea lice treatments. Production zone can be a proxy for several factors, including those not retained in the final mortality model (i.e. local biomass density and sea lice infestation), but overall they have been shown to be related to the prevalence of infectious diseases. We found that the highest mortality was in the zones 2,3 and 4 , which are the zones that have traditionally had problems with sea lice infestations, and diseases such as cardiomyopathy syndrome (CMS) and pancreatic disease (PD) ${ }^{4,5,57}$. For example, the estimated weekly louse larvae production per fish in zones 2, 3, and 4 were the highest and more than twice that estimated for most of the other zones ${ }^{4}$. The high sea lice infestation level can also indicate where delousing treatments associated with mortality are undertaken more frequently. It has been reported that fish groups from farms in southern and western Norwegian coastal waters, corresponding to the high mortality zones, were at higher risk of developing clinical $\mathrm{CMS}^{57}$. Regarding PD, there are two subtypes of the virus causing the disease in Norway (SAV 2 and SAV 3), with SAV3 being associated with higher mortality ${ }^{12}$. The SAV is endemic in just under half of the production zones, but almost all SAV 3 cases in Norway are detected within the zones 2,3 and $4^{4}$.

The use of baths with $\mathrm{H}_{2} \mathrm{O}_{2}$ or medicinal compounds as well as non-medicinal treatments against sea lice also contributed considerably to mortality. Overall, there was a decrease in the number of sea lice treatments from $2014(n=3000)$ to $2019(n=2678)$, despite of a slight increase in the number of fish harvested ${ }^{4}$. Notably, this has been accompanied by a dramatic shift away from medicinal bath treatments, driven by the development of resistance in sea lice ${ }^{6,40-42}$. In 2014, most of the treatments were medicinal baths and $\mathrm{H}_{2} \mathrm{O}_{2}(60 \%$ and $34 \%$, respectively), whereas in 2019 the majority were thermal and mechanical delousing ( $54 \%$ and $27 \%$, respectively $)^{4}$. Thus, we attribute the decline in the total number of sea lice treatments to the shift away from less effective bath treatments towards non-medicinal technologies which have become more effective in the last years ${ }^{6}$. Although bath treatments are less widely used, they are still an important risk factor for mortality. Activities associated with bath treatments, such as crowding of fish as well as loading and unloading of well boats, can induce a stress response in fish leading to increased mortality ${ }^{58}$. Studies argue that mortality solely related to medicinal applications does not occur following dosage recommendations ${ }^{59,60}$. However, with $\mathrm{H}_{2} \mathrm{O}_{2}$ there was increased mortality when baths were performed above $10^{\circ} \mathrm{C}^{39,61}$, which is a commonly registered temperature in production sites.

We found that the non-medicinal treatments were associated with the highest mortality in comparison with the other determinants. This is consistent with previous research that found mortality increases from 1 month to the next were mostly due to thermal and mechanical delousing compared with the other delousing methods used on Norwegian farms ${ }^{6}$. A study has quantified the effects of different delousing treatments on mortality, and found that 790 fish are expected to die within the first two weeks following a thermal treatment, as compared to 928 from mechanical treatments and 146 from medicinal treatments (based on sea cages with an average of 150,000 salmon and stocked in 2017) ${ }^{41}$. The negative impacts of the non-medicinal treatments on other fish welfare indicators have also raised concerns. There was an association between thermal delousing and snout and fin injuries in salmon ${ }^{43,44}$. Furthermore, salmon exposed to warm water at $28^{\circ} \mathrm{C}$ for $10 \mathrm{~s}$ probably suffered pain as indicated 
by behavioral changes, which is less time than the thermal treatments at $28-34{ }^{\circ} \mathrm{C}$ for $30 \mathrm{~s}$ used in farms $\mathrm{s}^{62}$. An unusual increase in skin bleeding and scale losses were observed in salmon treated by mechanical delousing ${ }^{43}$.

Non-medicinal treatments might be the only option for some farmers to adhere to regulations regarding control of sea lice, despite the understanding of their negative effects on fish welfare and mortality. Quantifying these effects has important implications for the use and development of other management strategies against sea lice that are probably less detrimental to salmon. This includes the preventative approach of sea cages with "skirts", which are already commonly used on some commercial farms. The "skirts" are manufactured with materials that minimize salmon contact with sea lice on the sea surface ${ }^{63}$. A meta-analysis study found just above $50 \%$ median reduction in sea lice infestation density related to the sea cages with "skirts" ${ }^{4}$. Biological control of sea lice using cleaner fish (e.g. Atlantic lumpfish (Cyclopterus lumpus), ballan wrasse (Labrus bergylta), goldsinny wrasse (Ctenolabrus rupestris) and corkwing wrasse (Symphodus melops)) that eat the parasite attached to salmon is another management strategy adopted by some farmers. It is estimated that 49.1 million cleaner fish were placed in sea cages with Atlantic salmon in $2019^{4}$. With regards to the success of cleaner fish in reducing sea lice infestation, there seem to be variations based on studies conducted in commercial scale farms ${ }^{65}$. Co-stocking cleaner fish with salmon failed to reduce sea lice counts ${ }^{66}$, whereas others found high reduction $(60-100 \%)$ in adult female lice counts compared with sea cages without cleaner fish ${ }^{67}$. It is noteworthy that the negative impacts of using cleaner fish, especially wild-caught wrasse, has been debated, due to the potential introduction and exchange of pathogens between different fish species stocked in the same sea cages ${ }^{4,68}$. In addition, the mortality of cleaner fish during their time spent in sea cages with the Atlantic salmon is extremely high. According to a survey performed in 2019, the median mortality of cleaner fish across Norway was $42 \%$, and so, there is a welfare issue with using these fish ${ }^{4}$.

Finally, temperature and salinity were the variables considered to evaluate exposure of salmon to adverse environmental conditions. Extremely high $\left(>22^{\circ} \mathrm{C}\right)$ or low $\left(<2^{\circ} \mathrm{C}\right)$ temperatures can be lethal to salmon ${ }^{69}$. We rarely observed these extreme temperatures in our study. However, we still found that temperature had a non-linear effect on mortality, and temperatures outside the optimal range of 5 and $10{ }^{\circ} \mathrm{C}$ were associated with increased mortality. When it comes to salinity, the recorded related data was often close to $33 \%$ ond values lower than that generally resulted in lower mortality. Prior studies on farmed Atlantic salmon focused on the influence of temperature and salinity in early post-smolts ${ }^{27,55,69,70}$. In the days after transfer, the osmoregulation of postsmolts in tanks with a salinity of $33 \%$ is likely to be impaired at both low temperatures $\left(4.1^{\circ} \mathrm{C} \text { and } 4.3^{\circ} \mathrm{C}\right)^{55,70}$ and high temperatures $\left(14.3^{\circ} \mathrm{C}\right)^{70}$, resulting in negative impacts on mortality. It is possible that absolute temperature and salinity do not necessarily affect salmon mortality directly. For example, salmon may be more sensitive to abrupt changes in temperature and respond differently to such changes depending on its life stage ${ }^{62,69}$, which we did not consider in our study.

A report from 2019 shows how an increase in mortality for larger fish happened during the period from 2009 to 2016, and this increase was greater at high temperatures ${ }^{71}$. We also cannot exclude the indirect effects of temperature and salinity on salmon mortality through their influence on the development of harmful algae $e^{29}$, ${ }^{30}$ and pathogens ${ }^{16,19,33}$, including L. salmonis ${ }^{31,32}$. A limitation to our study was that we were not able to assess other environmental variables due to a lack of nation-wide data. As pointed out by others ${ }^{7,72}$, reduced oxygen levels, strong water currents, predation, and algal blooms can have consequences for fish welfare and mortality. Although the explored environmental factors cannot be controlled in salmon production sea cages, their association with fish health is useful to monitor mortality.

The baseline mortality model raises the possibility for developing a syndromic surveillance system for farmed salmon. Syndromic surveillance uses data regularly updated to detect possible deviations from typical records that could be related to health problems in a population ${ }^{73}$. Such deviations demanding further attention might be detected in a timely manner using predictions from models that take into account the spatial-temporal patterns of mortality as well as its determinants for retrospective data analysis. Hence, interventions aiming to decrease salmon mortality might be feasible. The use of mortality data for syndromic surveillance is promising and has been explored mainly for cattle ${ }^{73,74}$.

\section{Conclusions}

This study has shown how some environmental, geographical, production and health determinants explain the baseline mortality of farmed salmon. The multivariable regression analysis revealed that the sea surface temperature and salinity were important environmental mortality determinants. There was higher mortality in some zones associated with more disease occurrence. Although increased mortality appeared in the first months after sea transfer of salmon, this problem was more noticeable later in the salmon production cycle. Several of the mortality determinants were connected to the intensive salmon production system. This included the period of the year when fish was first stocked at sea and practices undertaken to tackle major salmon diseases, especially sea lice treatments. There were considerable effects of applied treatments against sea lice on mortality using baths with $\mathrm{H}_{2} \mathrm{O}_{2}$ or medicinal compounds as well as non-medicinal delousing, the latter being more detrimental. It is promising to use the regularly reported data for mortality predictions. Thus, results of this study also offer the possibility to monitor mortality patterns for early detection of health problems in salmonids.

\section{Methods}

Study design and population. The production cycle of Norwegian salmon farming has a freshwater phase followed by a seawater phase. This study included only the seawater phase, from the time smolts are stocked at sea until they are slaughtered. The first stocking of smolts at sea is usually unevenly dispersed throughout the year, but smolts are more frequently stocked during spring and autumn months. Smolts are typically moved to sea cages when they are between 6 and 12 months old. The salmon are slaughtered after approximately 14 to 


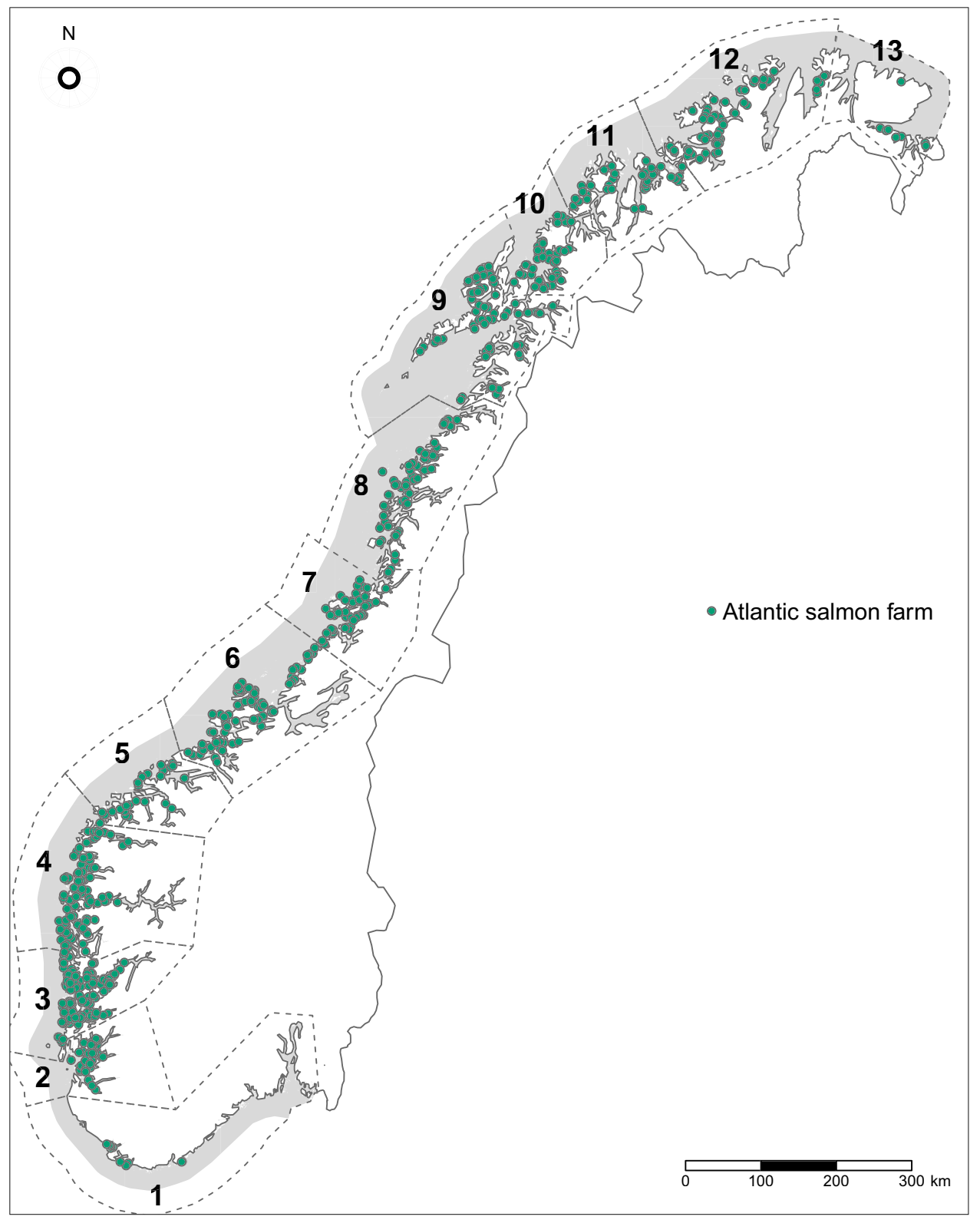

Figure 6. Geographical location of Atlantic salmon farms and production zones in Norway. The map shows all commercial farms for the purpose of food production registered between January 2014 and December 2019. The regions delimited by dashed lines represent the production zones $1-13$. This map was generated in $\mathrm{R}$, using the R packages sf $^{78}$ (version 0.9-7; https://cran.r-project.org/web/packages/sf/sf.pdf) and tmap ${ }^{79}$ (version 3.3-1; https://cran.r-project.org/web/packages/tmap/tmap.pdf).

18 months of life at sea. Longer periods of life at sea are possible depending on fish growth rates and the farmers' management preferences. When all cages on a farm are emptied, a minimum fallowing period of 2 months is obligatory in Norway before stocking a new fish cohort in the farm.

Our target population was Atlantic salmon (Salmo salar L.) from commercial farms in Norway, farmed for the purpose of food production. Figure 6 shows registered farms $(n=717)$ in the national database during the period of this study, between January 2014 and December 2019. During this period, the number of active farms per month ranged from 271 to 421 . These farms are distributed across 13 distinct production zones along all the Norwegian coast, established by regulations ${ }^{65}$. Common characteristics of farms located within a zone includes their water current connectivity and geographical location. The zones have been used for management decisions, for example, strategies towards minimizing the spread of sea lice ${ }^{75-77}$. The density of farms in each of the zones varies considerably.

We conducted a retrospective study using farm-level data. We used the count of dead fish for statistical inferences and predictions. Based on existing literature and discussions among the authors, we hypothesized determinants and their putative association with salmon mortality and summarized this in a directed acyclic graph (DAG) (Fig. 7). 


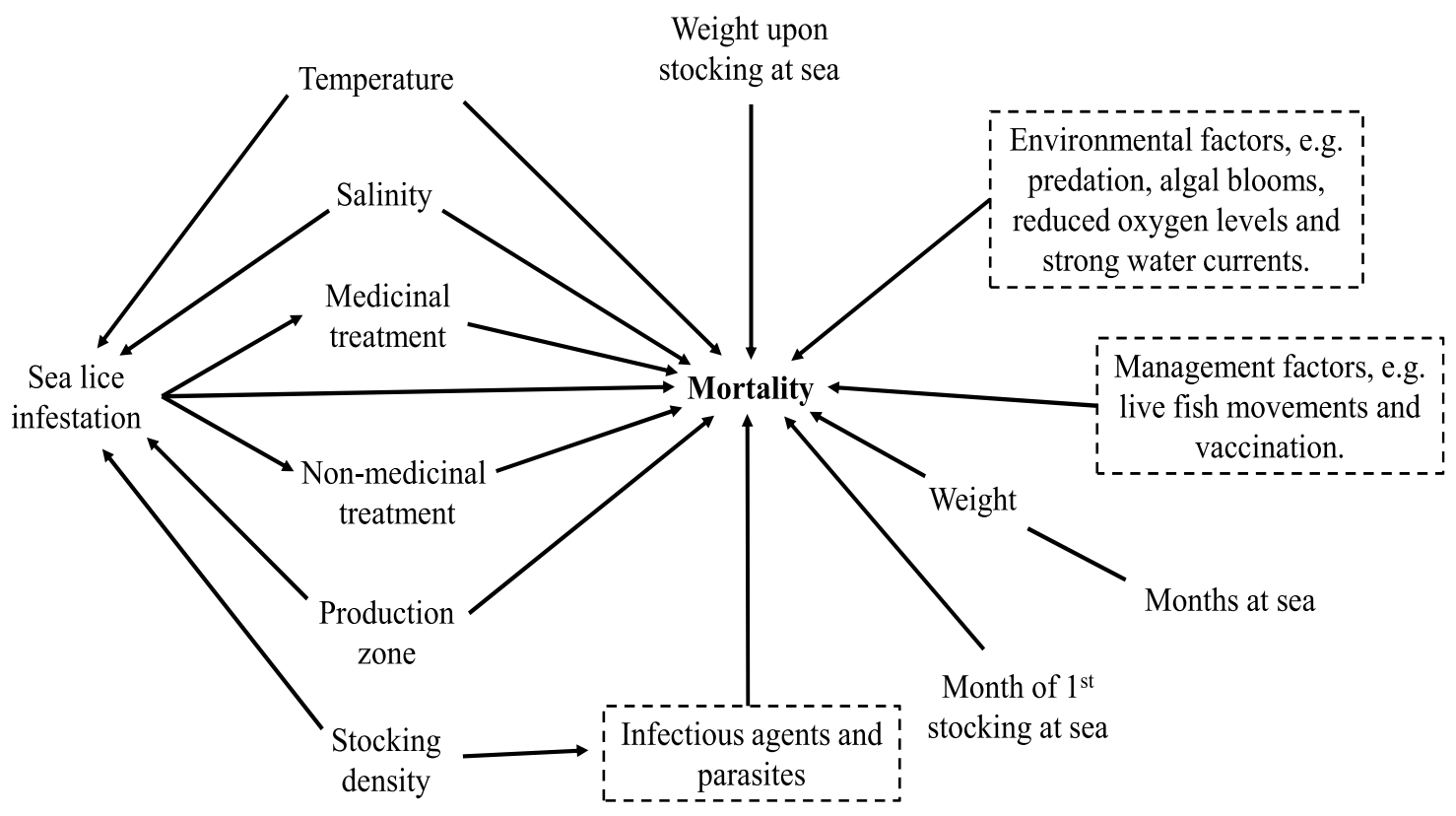

Figure 7. Directed acyclic graph (DAG) showing the putative determinants of baseline mortality in farmed Atlantic salmon. Dashed boxes represent unobserved factors.

Data sources and processing. We gathered environmental, fish health and production data. Farmers reported monthly data to the Norwegian Directorate of Fisheries, which were: stocking month, fish counts, deaths and other types of losses, and mean fish weight. Because there were few records from farms located in zone 13, we grouped data from zones 12 and 13 together. For some of the data, farmers reported to the Norwegian Food Safety Authority on weekly basis. Sea surface temperature is one of them. Another one was the sea lice infestation level data, which was based on the mean number of mature female sea lice. A minimum of 10 sampled fish from half of the cages, but no less than 2 cages per farm were considered for the sea lice counts reported between January 2012 and March 2017. From March 2017 onwards, sea lice counts were made across all cages. Sea lice treatments are required if the infestation level exceeds a threshold of 0.5 lice per salmon ${ }^{80,81}$. This threshold was reduced to 0.2 during spring after the regulations from 2017, due to the threat of sea lice to wild salmon smolt in their migration period to sea. The number of treatments applied to control sea lice was also acquired weekly and refers to two types. The first is bath treatments using $\mathrm{H}_{2} \mathrm{O}_{2}$ or medicinal compounds, usually azamethiphos, cypermethrin, and deltamethrin. The other is non-medicinal treatments, which included the removal of sea lice by flushing or brushing (mechanical delousing), warm water (thermal delousing) or freshwater baths. Farmers can use a web portal for data entry. Most commonly, commercial software is used for transferring data to the portal. We have access to those data through the Norwegian Food Safety Authority (not open access), but some of the data is available online (https://www.barentswatch.no/en/fishhealth/). Daily records of sea surface salinity (SSS) were provided by the Institute of Marine Research, and were estimated from the NorKyst 800 hydrodynamic ocean model ${ }^{82}$. The SSS in a farm on a day matched with the SSS estimated in the closest geographic coordinates.

We processed and analyzed the data using $\mathrm{R}$ statistical software version 4.0.2 $2^{47}$. Farm registration numbers and geocoded coordinates were unique identifiers in the datasets, available online (www.fiskeridir.no). We used the tidyverse collection of packages to manage and visualize data ${ }^{46}$; the packages sf and tmap for generating a map with the study farms ${ }^{78,79}$ and the ncdf4 package $^{83}$ for reading the SSS data from NetCDF format. Data inputs on a weekly and daily basis were converted into monthly records using the mean of values related to a month. An overview of variables and their scale used in this study can be found as Supplementary Table S2.

The complete dataset had 26,285 monthly records from salmon cohorts before we applied exclusion criteria. We excluded data with inconsistencies when, in the same month, the number of deaths was larger than the fish count (number of monthly records $(n)=16$ ). In addition, we disregarded records where the number of counted fish in a month did not match with the expected number after the removal of fish losses from the previous month $(n=7003)$. There was also an exclusion of records from cohorts where fish had a mean initial start weight higher than $500 \mathrm{~g}(n=1394)$. The listed inconsistencies could be related to farm management practices, including live fish movements between cages or farms, splitting of production cohorts, and multiple stocking or slaughtering events. In such cases, it was likely that fish had not spent the whole production cycle at sea on the same farm. Therefore, we would not have reliable data regarding their retrospective exposure to putative mortality determinants. We further excluded records that did not represent salmon from a typical farm for commercial purposes, i.e. records from months when fish had more than 24 months spent at sea $(n=26)$ and with fish weighing more than $6 \mathrm{~kg}(n=56)$. Because our objective was to model baseline mortality, we excluded records when the monthly mortality rate (see next section) was higher than $2 \%(n=3510)$. We set this limit for baseline mortality based on reports that described the mortality patterns in salmon aquaculture in Norway ${ }^{2,6}$ and elsewhere ${ }^{1,3,7}$. Using Norwegian reports to illustrate ${ }^{2,71}$, the mean monthly mortality was generally below $2 \%$, in three-quarters of the 
salmon cohorts produced in sea cages between 2014 and $2018^{2}$. The final dataset for analysis comprised 14,280 records after the exclusions, which corresponded to $54.3 \%$ of the data obtained during the study period. This data referred to approximately $90 \%(642 / 717)$ of the farms in our target population.

Statistical analysis. Fish mortality is described as mortality rates in this paper. We calculated the monthly mortality rate (MR) using the following equation, with an approximate calculation of the number of fish units at risk for the established period of time in the denominator ${ }^{84}$ :

$$
M R=\frac{\text { deaths }}{\left(\text { start }-\frac{\text { deaths }}{2}-\frac{w t h}{2}+\frac{\text { add }}{2}\right) * \text { time }},
$$

where deaths is the number of dead fish in a month; start is the number of fish at risk at the beginning of the month; wth is the number of withdrawn fish from the population; add is the number of added fish to the population; and time is one month.

For descriptive purposes, we produced plots with fitted local polynomial regression (LOESS) curves and tables with the calculated mortality rates and its distribution over the variables included in the DAG.

We implemented generalized linear mixed models using the glmmTMB package ${ }^{85}$. Our outcome was the number of dead fish, which we modelled using negative binomial regressions, suitable for count data. The negative binomial regression also accounted for overdispersion in the data, which we confirmed after fitting quasipoisson models that revealed large dispersion parameters. We log transformed the number of fish at risk every month [the denominator in Eq. (1)] and used it as an offset term in the right hand side of models. We included the putative mortality determinants as explanatory variables in the model as fixed effects. We also included farm as a random effect to account for repeated measures. The model is defined as follows:

$$
\begin{gathered}
Y_{i}=N B\left(\mu_{i}, k\right) \\
E\left(Y_{i}\right)=\mu_{i} \\
\operatorname{var}\left(Y_{i}\right)=\mu_{i}+\mu_{i}^{2} / k \\
\log \left(\mu_{i}\right)=\beta_{0}+X_{i} \beta+\log \left(t_{i}\right)+\gamma_{\text {farm }}+\varepsilon_{i} \\
\gamma_{\text {farm }} \sim N\left(0, \sigma_{\text {farm }}^{2}\right),
\end{gathered}
$$

where $Y_{i}$ is the number of dead fish per month in farm $i, \mu_{i}$ is the expected number of deaths, $k$ is the dispersion parameter, $\beta_{0}$ is the intercept, $X_{i}$ is the matrix of variables, $\beta$ is the vector of regression coefficients, $t_{i}$ is the fishtime units at risk per month in farm $i$, and $\gamma_{\text {farm }}$ is the random effect of farm.

We began model selection with a global model including the explanatory variables described in Supplementary Table S2 online. We included interactions and polynomial terms in the model if applicable. In each step, we eliminated the variable with the weakest association with the outcome. The variables retained had an association with the outcome at a 5\% significance level based on results of likelihood ratio tests. Furthermore, we calculated the variance inflation factor of the variables to check for collinearity problems. We selected the final model based on the Akaike information criterion. We assessed potential model confounders by excluding variables from the final model one by one and refitting the model. We considered a variable to have confounding effects if after its exclusion there was a change greater than $20 \%$ in at least one of the regression coefficients when comparing it to the final model results. The potential confounders were kept in the final model. Model results consisted of estimated regression coefficients and $95 \%$ profile likelihood confidence intervals. We estimated the contribution of the random effect to the model by computing the intra-class correlation coefficient using the performance package $^{86}$. We visualized the model results using plots of the predicted number of fish deaths versus generated values for the variables in our final model.

For model validation, we ran 1000 simulations to produce standardized residuals using the DHARMa package ${ }^{87}$. We then visually inspected the residuals plotted against the fitted values, and against each of the explanatory variables.

\section{Data availability}

Part of the data used is routinely updated and publicly available online (www.barentswatch.no/en/fishhealth/, www.fiskeridir.no and www.kartverket.no). Some of the production data cannot be made public because of privacy agreements. R code used for descriptive results, analysis, models diagnostics and creating figures is available (https://doi.org/10.5281/zenodo.4309632).

Received: 22 December 2020; Accepted: 30 June 2021

Published online: 19 July 2021

\section{References}

1. SERNAPESCA (Servicio Nacional de Pesca y Acuicultura). Informe Sanitario de Salmonicultura. http://www.sernapesca.cl/sites/ default/files/informe_sanitario_salmonicultura_en_centros_marinos_2018_final.pdf (2018). 
2. Bang Jensen, B., Qviller, L. \& Toft, N. Spatio-temporal variations in mortality during the seawater production phase of Atlantic salmon (Salmo salar) in Norway. J. Fish Dis. 43, 445-457 (2020).

3. Moriarty, M. et al. Modelling temperature and fish biomass data to predict annual Scottish farmed salmon, Salmo salar L., losses: Development of an early warning tool. Prev. Vet. Med. 178, 104985. https://doi.org/10.1016/j.prevetmed.2020.104985 (2020).

4. Sommerset, I. et al. The Health Situation in Norwegian Aquaculture 2019. https://www.vetinst.no/rapporter-og-publikasjoner/ rapporter/2020/fiskehelserapporten-2019 (2020).

5. Grefsrud, E. S. et al. Risikorapport norsk fiskeoppdrett 2021-risikovurdering. https://www.hi.no/hi/nettrapporter/rapport-fra-havfo rskningen-2021-8 (2021).

6. Overton, K. et al. Salmon lice treatments and salmon mortality in Norwegian aquaculture: A review. Rev. Aquac. 11, 1398-1417 (2019).

7. Soares, S., Green, D. M., Turnbull, J. F., Crumlish, M. \& Murray, A. G. A baseline method for benchmarking mortality losses in Atlantic salmon (Salmo salar) production. Aquaculture 314, 7-12 (2011).

8. Santurtun, E., Broom, D. \& Phillips, C. A review of factors affecting the welfare of Atlantic salmon (Salmo salar). Anim. Welf. 27, 193-204 (2018).

9. Ellis, T., Berrill, I., Lines, J., Turnbull, J. F. \& Knowles, T. G. Mortality and fish welfare. Fish Physiol. Biochem. 38, 189-199 (2012).

10. Crockford, T., Menzies, F., McLoughlin, M., Wheatley, S. \& Goodall, E. Aspects of the epizootiology of pancreas disease in farmed Atlantic salmon Salmo salar in Ireland. Dis. Aquat. Organ. 36, 113-119 (1999).

11. Stormoen, M., Kristoffersen, A. B. \& Jansen, P. A. Mortality related to pancreas disease in Norwegian farmed salmonid fish, Salmo salar L. and Oncorhynchus mykiss (Walbaum). J. Fish Dis. 36, 639-645 (2013).

12. Taksdal, T. et al. Mortality and weight loss of Atlantic salmon, Salmon salar L., experimentally infected with salmonid alphavirus subtype 2 and subtype 3 isolates from Norway. J. Fish Dis. 38, 1047-1061 (2015).

13. Hammell, K. L. \& Dohoo, I. R. Mortality patterns in infectious salmon anaemia virus outbreaks in New Brunswick, Canada. J. Fish Dis. 28, 639-650 (2005).

14. Glover, K. A. et al. Size-dependent susceptibility to infectious salmon anemia virus (ISAV) in Atlantic salmon (Salmo salar L.) of farm, hybrid and wild parentage. Aquaculture 254, 82-91 (2006).

15. Roberts, R. J. \& Pearson, M. D. Infectious pancreatic necrosis in Atlantic salmon, Salmo salar L. J. Fish Dis. 28, 383-390 (2005).

16. Bang Jensen, B. \& Kristoffersen, A. Risk factors for outbreaks of infectious pancreatic necrosis (IPN) and associated mortality in Norwegian salmonid farming. Dis. Aquat. Organ. 114, 177-187 (2015).

17. Brun, E., Poppe, T., Skrudland, A. \& Jarp, J. Cardiomyopathy syndrome in farmed Atlantic salmon Salmo salar: Occurrence and direct financial losses for Norwegian aquaculture. Dis. Aquat. Organ. 56, 241-247 (2003).

18. Bang Jensen, B., Brun, E., Fineid, B., Larssen, R. \& Kristoffersen, A. Risk factors for cardiomyopathy syndrome (CMS) in Norwegian salmon farming. Dis. Aquat. Organ. 107, 141-150 (2013).

19. Løvoll, M. et al. Atlantic salmon bath challenged with Moritella viscosa-Pathogen invasion and host response. Fish Shellfish Immunol. 26, 877-884 (2009).

20. Delghandi, M. R., El-Matbouli, M. \& Menanteau-Ledouble, S. Renibacterium salmoninarum-The causative agent of bacterial kidney disease in salmonid fish. Pathogens 9, 845. https://doi.org/10.3390/pathogens9100845 (2020).

21. Lhorente, J. P., Gallardo, J. A., Villanueva, B., Carabaño, M. J. \& Neira, R. Disease resistance in Atlantic Salmon (Salmo salar): Coinfection of the intracellular bacterial pathogen Piscirickettsia salmonis and the Sea Louse Caligus rogercresseyi. PLoS ONE $\mathbf{9}$, e95397. https://doi.org/10.1371/journal.pone.0095397 (2014).

22. Kristoffersen, A. B. et al. Quantitative risk assessment of salmon louse-induced mortality of seaward-migrating post-smolt Atlantic salmon. Epidemics 23, 19-33 (2018).

23. Vollset, K. W. Parasite induced mortality is context dependent in Atlantic salmon: Insights from an individual-based model. Sci. Rep. 9, 17377. https://doi.org/10.1038/s41598-019-53871-2 (2019).

24. Taylor, R. S., Kube, P. D., Muller, W. J. \& Elliott, N. G. Genetic variation of gross gill pathology and survival of Atlantic salmon (Salmo salar L.) during natural amoebic gill disease challenge. Aquaculture 294, 172-179 (2009).

25. Carvalho, L. A. et al. Impact of co-infection with Lepeophtheirus salmonis and Moritella viscosa on inflammatory and immune responses of Atlantic salmon (Salmo salar). J. Fish Dis. 43, 459-473 (2020).

26. Barker, S. E. et al. Sea lice, Lepeophtheirus salmonis (Krøyer 1837), infected Atlantic salmon (Salmo salar L.) are more susceptible to infectious salmon anemia virus. PLoS ONE 14, e0209178. https://doi.org/10.1371/journal.pone.0209178 (2019).

27. Staurnes, M., Sigholt, T., Åsgård, T. \& Baeverfjord, G. Effects of a temperature shift on seawater challenge test performance in Atlantic salmon (Salmo salar) smolt. Aquaculture 201, 153-159 (2001).

28. Ytrestøyl, T. et al. Performance and welfare of Atlantic salmon, $<\mathrm{scp}>$ Salmo salar $</ \mathrm{scp}>$ L. post-smolts in recirculating aquaculture systems: Importance of salinity and water velocity. J. World Aquac. Soc. 51, 373-392 (2020).

29. Montes, R. M., Rojas, X., Artacho, P., Tello, A. \& Quiñones, R. A. Quantifying harmful algal bloom thresholds for farmed salmon in southern Chile. Harmful Algae 77, 55-65 (2018).

30. León-Muñoz, J., Urbina, M. A., Garreaud, R. \& Iriarte, J. L. Hydroclimatic conditions trigger record harmful algal bloom in western Patagonia (summer 2016). Sci. Rep. 8, 1330. https://doi.org/10.1038/s41598-018-19461-4 (2018).

31. Groner, M. L., McEwan, G. F., Rees, E. E., Gettinby, G. \& Revie, C. W. Quantifying the influence of salinity and temperature on the population dynamics of a marine ectoparasite. Can. J. Fish. Aquat. Sci. 73, 1281-1291 (2016).

32. Sievers, M., Oppedal, F., Ditria, E. \& Wright, D. W. The effectiveness of hyposaline treatments against host-attached salmon lice. Sci. Rep. 9, 6976. https://doi.org/10.1038/s41598-019-43533-8 (2019).

33. Tunsjø, H. S. et al. Adaptive response to environmental changes in the fish pathogen Moritella viscosa. Res. Microbiol. 158, 244-250 (2007).

34. Guomundsdóttir, S. et al. Measures applied to control Renibacterium salmoninarum infection in Atlantic salmon: A retrospective study of two sea ranches in Iceland. Aquaculture 186, 193-203 (2000).

35. Jansen, M. D. et al. Salmonid alphavirus (SAV) and pancreas disease (PD) in Atlantic salmon, Salmo salar L., in freshwater and seawater sites in Norway from 2006 to 2008. J. Fish Dis. 33, 391-402 (2010).

36. Jensen, B. B., Kristoffersen, A. B., Myr, C. \& Brun, E. Cohort study of effect of vaccination on pancreas disease in Norwegian salmon aquaculture. Dis. Aquat. Organ. 102, 23-31 (2012).

37. Karlsen, C., Thorarinsson, R., Wallace, C., Salonius, K. \& Midtlyng, P. J. Atlantic salmon winter-ulcer disease: Combining mortality and skin ulcer development as clinical efficacy criteria against Moritella viscosa infection. Aquaculture 473, 538-544 (2017).

38. Jansen, P. A. et al. Sea lice as a density-dependent constraint to salmonid farming. Proc. R. Soc. B Biol. Sci. 279, 2330-2338 (2012).

39. Overton, K., Samsing, F., Oppedal, F., Stien, L. H. \& Dempster, T. Lowering treatment temperature reduces salmon mortality: A new way to treat with hydrogen peroxide in aquaculture. Pest Manag. Sci. 74, 535-540 (2018).

40. Helgesen, K. O., Romstad, H., Aaen, S. M. \& Horsberg, T. E. First report of reduced sensitivity towards hydrogen peroxide found in the salmon louse Lepeophtheirus salmonis in Norway. Aquac. Rep. 1, 37-42 (2015).

41. Walde, C. S., Bang Jensen, B., Pettersen, J. M. \& Stormoen, M. Estimating cage level mortality distributions following different delousing treatments of Atlantic salmon (Salmo salar) in Norway. J. Fish Dis. 44, jfd.13348. https://doi.org/10.1111/jfd.13348 (2021).

42. Aaen, S. M., Helgesen, K. O., Bakke, M. J., Kaur, K. \& Horsberg, T. E. Drug resistance in sea lice: A threat to salmonid aquaculture. Trends Parasitol. 31, 72-81 (2015). 
43. Gismervik, K., Nielsen, K. V., Lind, M. B. \& Viljugrein, H. Mekanisk avlusing med FLS-avlusersystem-dokumentasjon av fiskevelferd og effekt mot lus. Veterincerinstituttets rapportserie 6-2017. See https://www.vetinst.no/rapporter-og-publikasjoner/rappo rter/2017/mekanisk-avlusing-dokumentasjon-av-fiskevelferd-og-effekt-mot-lus (2017).

44. Grøntvedt, R. N. et al. Thermal de-licing of salmonid fish-Documentation of fish welfare and effect. Norwegian Veterinary Institute 's Report series 13-2015. https://www.vetinst.no/rapporter-og-publikasjoner/rapporter/2015/thermal-de-licing-of-salmo nid-fish-documentation-of-fish-welfare-and-effect (2015).

45. Gismervik, K. et al. Thermal injuries in Atlantic salmon in a pilot laboratory trial. Vet. Anim. Sci. 8, 100081. https://doi.org/10. 1016/j.vas.2019.100081 (2019).

46. Wickham, H. et al. Welcome to the Tidyverse. J. Open Source Softw. 4, 1686. https://doi.org/10.21105/joss.01686 (2019).

47. R Core Team. R: A Language and Environment for Statistical Computing (R Foundation for Statistical Computing, 2020).

48. Auguie B. gridExtra: Miscellaneous functions for "grid" graphics. R package version 2.3. https://CRAN.R-project.org/package= gridExtra (2017).

49. Salama, N. K. G., Murray, A. G., Christie, A. J. \& Wallace, I. S. Using fish mortality data to assess reporting thresholds as a tool for detection of potential disease concerns in the Scottish farmed salmon industry. Aquaculture 450, 283-288 (2016).

50. Aunsmo, A. et al. Methods for investigating patterns of mortality and quantifying cause-specific mortality in sea-farmed Atlantic salmon Salmo salar. Dis. Aquat. Organ. 81, 99-107 (2008).

51. Usher, M. L., Talbot, C. \& Eddy, F. B. Effects of transfer to seawater on growth and feeding in Atlantic salmon smolts (Salmo salar L.). Aquaculture 94, 309-326 (1991).

52. Johansson, L.-H., Timmerhaus, G., Afanasyev, S., Jørgensen, S. M. \& Krasnov, A. Smoltification and seawater transfer of Atlantic salmon (Salmo salar L.) is associated with systemic repression of the immune transcriptome. Fish Shellfish Immunol. 58, 33-41 (2016).

53. Ellis, T., Turnbull, J. F., Knowles, T. G., Lines, J. A. \& Auchterlonie, N. A. Trends during development of Scottish salmon farming: An example of sustainable intensification?. Aquaculture 458, 82-99 (2016).

54. Kristensen, T. et al. Effects of production intensity and production strategies in commercial Atlantic salmon smolt (Salmo salar L.) production on subsequent performance in the early sea stage. Fish Physiol. Biochem. 38, 273-282 (2012).

55. Handeland, S. O., Björnsson, B. T., Arnesen, A. M. \& Stefansson, S. O. Seawater adaptation and growth of post-smolt Atlantic salmon (Salmo salar) of wild and farmed strains. Aquaculture 220, 367-384 (2003).

56. Bjørndal, T. \& Tusvik, A. Economic analysis of on-growing of salmon post-smolts. Aquac. Econ. Manag. 24, 355-386 (2020).

57. Bang Jensen, B., Mårtensson, A. \& Kristoffersen, A. B. Estimating risk factors for the daily risk of developing clinical cardiomyopathy syndrome (CMS) on a fishgroup level. Prev. Vet. Med. 175, 104852. https://doi.org/10.1016/j.prevetmed.2019.104852 (2020).

58. Iversen, M. et al. Stress responses in Atlantic salmon (Salmo salar L.) smolts during commercial well boat transports, and effects on survival after transfer to sea. Aquaculture 243, 373-382 (2005).

59. Intorre, L. Safety of azamethiphos in eel, seabass and trout. Pharmacol. Res. 49, 171-176 (2004).

60. Olsvik, P. A., Ørnsrud, R., Lunestad, B. T., Steine, N. \& Fredriksen, B. N. Transcriptional responses in Atlantic salmon (Salmo salar) exposed to deltamethrin, alone or in combination with azamethiphos. Comp. Biochem. Physiol. Part C Toxicol. Pharmacol. 162, 23-33 (2014).

61. Johnson, S., Constible, J. \& Richard, J. Laboratory investigations on the efficacy of hydrogen peroxide against the salmon louse Lepeophtheirus salmonis and its lexicological and histopathological effects on Atlantic salmon Salmo salar and Chinook salmon Oncorhynchus tshawytscha. Dis. Aquat. Organ. 17, 197-204 (1993).

62. Nilsson, J. et al. Sudden exposure to warm water causes instant behavioural responses indicative of nociception or pain in Atlantic salmon. Vet. Anim. Sci. 8, 100076. https://doi.org/10.1016/j.vas.2019.100076 (2019).

63. Stien, L. H., Lind, M. B., Oppedal, F., Wright, D. W. \& Seternes, T. Skirts on salmon production cages reduced salmon lice infestations without affecting fish welfare. Aquaculture 490, 281-287 (2018).

64. Barrett, L. T., Oppedal, F., Robinson, N. \& Dempster, T. Prevention not cure: A review of methods to avoid sea lice infestations in salmon aquaculture. Rev. Aquac. 12, 2527-2543 (2020).

65. Overton, K., Barrett, L. T., Oppedal, F., Kristiansen, T. S. \& Dempster, T. Sea lice removal by cleaner fish in salmon aquaculture: A review of the evidence base. Aquac. Environ. Interact. 12, 31-44 (2020).

66. Tully, O., Daly, P., Lysaght, S., Deady, S. \& Varian, S. J. A. Use of cleaner-wrasse (Centrolabrus exoletus (L.) and Ctenolabrus rupestris (L.)) to control infestations of Caligus elongatus Nordmann on farmed Atlantic salmon. Aquaculture 142, 11-24 (1996).

67. Imsland, A. K. D. et al. It works! Lumpfish can significantly lower sea lice infestation in large-scale salmon farming. Biol. Open 7, bio036301. https://doi.org/10.1242/bio.036301 (2018).

68. Erkinharju, T., Dalmo, R. A., Hansen, M. \& Seternes, T. Cleaner fish in aquaculture: Review on diseases and vaccination. Rev. Aquac. 13, 189-237 (2021).

69. Elliott, J. M. \& Elliott, J. A. Temperature requirements of Atlantic salmon Salmo salar, brown trout Salmo trutta and Arctic charr Salvelinus alpinus: Predicting the effects of climate change. J. Fish Biol. 77, 1793-1817 (2010).

70. Finstad, T. \& Sigholt, B. Effect of low temperature on seawater tolerance in Atlantic salmon (Salmo salar) smolts. Aquaculture 84, 167-172 (1990).

71. Grefsrud, E. S. et al. Risikorapport norsk fiskeoppdrett 2018. https://www.hi.no/resources/publikasjoner/risikorapport-norsk-fiske oppdrett/2018/risikorapport_2018.pdf (2018).

72. Hvas, M., Folkedal, O. \& Oppedal, F. Fish welfare in offshore salmon aquaculture. Rev. Aquac. 13, 836-852 (2021).

73. Dórea, F. C. \& Vial, F. Animal health syndromic surveillance: A systematic literature review of the progress in the last 5 years (2011-2016). Vet. Med. Res. Rep. 7, 157-170 (2016).

74. Fernández-Fontelo, A. et al. Enhancing the monitoring of fallen stock at different hierarchical administrative levels: An illustration on dairy cattle from regions with distinct husbandry, demographical and climate traits. BMC Vet. Res. 16, 110 (2020).

75. Samsing, F., Johnsen, I., Dempster, T., Oppedal, F. \& Treml, E. A. Network analysis reveals strong seasonality in the dispersal of a marine parasite and identifies areas for coordinated management. Landsc. Ecol. 32, 1953-1967 (2017).

76. Samsing, F., Johnsen, I., Treml, E. A. \& Dempster, T. Identifying 'firebreaks' to fragment dispersal networks of a marine parasite. Int. J. Parasitol. 49, 277-286 (2019).

77. Myksvoll, M. S. et al. Evaluation of a national operational salmon lice monitoring system-From physics to fish. PLoS ONE 13, e0201338. https://doi.org/10.1371/journal.pone.0201338 (2018).

78. Pebesma, E. Simple features for R: Standardized support for spatial vector data. R J. 10, 439-446 (2018).

79. Tennekes, M. tmap: Thematic maps in R. J. Stat. Softw. 84, 1-39 (2018).

80. NFD (Nærings- og fiskeridepartementet). Forskrift om bekjempelse av lakselus i akvakulturanlegg. Lovdata. https://lovdata.no/ dokument/SF/forskrift/2012-12-05-1140 (2012).

81. NFD (Nærings- og fiskeridepartementet). Forskrift om bekjempelse av lakselus i akvakulturanlegg. Lovdata. https://lovdata.no/ dokument/LTI/forskrift/2012-12-05-1140 (2012).

82. Asplin, L., Albretsen, J., Johnsen, I. A. \& Sandvik, A. D. The hydrodynamic foundation for salmon lice dispersion modeling along the Norwegian coast. Ocean Dyn. 70, 1151-1167 (2020).

83. Pierce, D. ncdf4: Interface to Unidata netCDF (Version 4 or Earlier) Format Data Files. CRAN. https://cran.r-project.org/web/ packages/ncdf4/ncdf4.pdf (2019). 
84. Dohoo I., Martin W. \& Stryhn H. Veterinary Epidemiologic Research (2nd edn) Charlottetown, Prince Edward Island (VER Inc., 2009).

85. Brooks, M. E. et al. glmmTMB balances speed and flexibility among packages for zero-inflated generalized linear mixed modeling. R J. 9, 378-400 (2017).

86. Lüdecke, D., Makowski, D., Waggoner, P. \& Patil, I. performance: Assessment of regression models performance. CRAN. https:// easystats.github.io/performance (2020).

87. Hartig, F. DHARMa: Residual diagnostics for hierarchical (multi-level/mixed) regression models. CRAN. https://cran.r-project. org/web/packages/DHARMa/DHARMa.pdf (2020).

\section{Acknowledgements}

We are grateful to Jon Albretsen (Institute of Marine Research in Norway) who provided the salinity data. We also thank our colleagues from the Norwegian Veterinary Institute Leif C. Stige who assisted with the handling of the salinity data and Hildegunn Viljugrein who participated in interpreting the model diagnostic plots.

\section{Author contributions}

V.H.S.O., K.R.D., L.Q. and B.B.J. designed this study. V.H.S.O. performed the data processing and analysis with inputs from K.R.D., L.Q., C.K. and B.B.J. V.H.S.O. wrote the first draft of the manuscript. K.R.D., L.Q., C.K. and B.B.J contributed substantially to the revision and editing of the manuscript. All authors approved the final version of the manuscript.

\section{Funding}

This study was part of the project "Understanding and monitoring mortality in farmed fish towards sustainable growth in aquaculture" (Project Number 294647) funded by the Research Council of Norway.

\section{Competing interests}

The authors declare no competing interests.

\section{Additional information}

Supplementary Information The online version contains supplementary material available at https://doi.org/ 10.1038/s41598-021-93874-6.

Correspondence and requests for materials should be addressed to V.H.S.O.

Reprints and permissions information is available at www.nature.com/reprints.

Publisher's note Springer Nature remains neutral with regard to jurisdictional claims in published maps and institutional affiliations.

(c) (i)

Open Access This article is licensed under a Creative Commons Attribution 4.0 International License, which permits use, sharing, adaptation, distribution and reproduction in any medium or format, as long as you give appropriate credit to the original author(s) and the source, provide a link to the Creative Commons licence, and indicate if changes were made. The images or other third party material in this article are included in the article's Creative Commons licence, unless indicated otherwise in a credit line to the material. If material is not included in the article's Creative Commons licence and your intended use is not permitted by statutory regulation or exceeds the permitted use, you will need to obtain permission directly from the copyright holder. To view a copy of this licence, visit http://creativecommons.org/licenses/by/4.0/.

(C) The Author(s) 2021 